\title{
Mulheres nas prisóes brasileiras: tensões entre a ordem disciplinar punitiva e as prescrições da maternidade
}

| ${ }^{1}$ Vilma Diuana, ${ }^{2}$ Marilena C.D.V. Corrêa, ${ }^{3}$ Miriam Ventura |

Resumo: Visando contribuir para o debate

1 Coordenação de Psicologia, Secretaria de Administração acerca da maternidade na prisão, este estudo analisou as interseçôes das normas de gênero e das relações disciplinares nesse contexto, identificando controvérsias no plano dos valores e das relações de poder que as sustentam. Para tal, entrevistou, em quatro estados brasileiros, 22 mulheres - gestantes e mães com filhos na prisão - e 19 profissionais que atuam nesse ambiente, além de cinco grupos com gestantes e mães e três com profissionais de saúde. Observou-se que o fechamento institucional, regulamentações penais, vigilância constante, restrição do poder decisório das mães e a separação compulsória dos filhos geram tensionamentos e promovem formas peculiares de viver a maternidade. Produziram-se três categorias analíticas distintas: maternidade interrompida, maternidade desautorizada e maternidade exclusiva. Concluiu-se que os mecanismos disciplinares característicos do penitenciário, ao se integrar às práticas de controle de si que as mulheres-mães realizam em função do cuidado e proteção dos filhos, vulnerabilizam concretamente estas mulheres, expondo-as e a seus filhos a sofrimentos psíquicos e morais. Sugere-se a necessidade de intervençôes normativas e medidas legais, além de políticas públicas que substituam a intervenção penal como estratégia de controle da pobreza e de outras formas de vida contestadas.

> Palavras-chave: gênero; mulheres; maternidade; parentalidade; prisão; direitos. 


\section{Introdução}

No Brasil, observa-se um crescimento acelerado do encarceramento feminino que vem tirando da invisibilidade as questôes colocadas pela prisão de mulheres. Enquanto a população prisional masculina cresceu 220,2\%, entre os anos 2000 e 2014, o número de mulheres custodiadas no sistema penitenciário aumentou 567,4\%, no mesmo período, alcançando 37.380 mulheres privadas de liberdade no país (BRASIL, 2014).

Em sua maioria, elas são jovens, negras e pardas, pobres, com baixa escolaridade, vivendo nos bairros mais carentes das grandes cidades. Delas, 68\% foram presas por crimes relacionados ao tráfico de drogas, muitas vezes por morarem junto com os companheiros e filhos em casas onde as drogas estavam sendo guardadas ou ainda por estarem levando drogas para o companheiro ou filho na prisão. Em 30\% dos casos, elas estão presas sem sentença condenatória, o que traduz a banalização do encarceramento, que, de acordo com os princípios internacionais do direito, deveria ser o último recurso do tratamento penal das tensões sociais, e a grave violação do direito de acesso à justiça destas mulheres já atingidas por um amplo processo de exclusão social.

$\mathrm{O}$ aumento do encarceramento feminino ampliou também a visibilidade do problema colocado pela existência de gestantes e mães que convivem com seus filhos nas prisões. Este fato, associado a novas legislações internacionais (ONU, 2010) e à atuação de movimentos sociais de mulheres (BRASIL, 2008), contribuiu para que ocorressem mudanças na legislação nacional, no que tange a esta população especialmente vulnerável, principalmente a partir de 2009. Tais mudanças refletem argumentos que têm por base os valores da maternidade, os direitos à proteção da infância, a equidade de gênero e as responsabilidades do Estado para com a saúde da mulher presa e seu filho. Trata-se, portanto, de referenciais éticos que podem se apoiar no valor da vida e em sua potência para transformar as políticas e práticas neste campo (ARÁN; PEIXOTO JR., 2007), mas que também envolvem papéis historicamente definidos e delimitados por categorias sociais naturalizadas em normas de gênero que marcam a mulher com as insígnias da maternidade, legitimando e valorizando certos modos de ser mãe, perante outros, que são desvalorizados e deslegitimados (CORRÊA; ARÁN, 2008).

No contexto prisional brasileiro, de modo geral, as gestantes privadas de liberdade são transferidas, por volta dos oito meses de gestação, para unidade 
prisional localizada na capital do estado onde, após o parto em hospital publico,

vão permanecer com seus filhos. Os espaços destinados à convivência mãe-filho diferem bastante entre os estados da federação, encontrando-se tanto unidades prisionais exclusivamente destinadas a este fim quanto alas, galerias ou prédios separados em penitenciárias femininas. $\mathrm{O}$ tempo de permanência da criança junto à mãe também difere. Há estados onde as crianças podem permanecer com suas mães depois de um ano de idade e outros em que o tempo permitido varia desde seis meses até um ano. Passada essa faixa etária, caso a mãe não obtenha a liberdade, seus filhos devem ser encaminhados à família, que ficará responsável pela guarda provisória da criança ou, ainda, nos casos em que isso não é possível, à instituição de abrigo.

Submetidas à "tutela" do Estado, que lhes diz que, estando grávidas, devem ser mães, e que, sendo mães, devem cuidar e amamentar seus filhos, e ainda que, quando isto lhes for determinado, devem entregá-los a cuidados de terceiros, estas mulheres, que, em 96\% dos casos (LEAL, 2016), foram presas grávidas, vivem a maternidade num contexto fortemente controlado e hierarquizado, em que recebem a "missão" de cuidar e proteger seus filhos sem o poder decisório e a liberdade de ação necessários para fazê-lo, vulnerabilizando-as e violando seus direitos reprodutivos (DIUANA, 2016).

O tema da maternidade na prisão envolve, portanto, além da discussão da divisão de papéis sexuais e o papel social da família, a condição de privação de liberdade da mulher e as relações de poder, hierárquicas e assimétricas, de diferentes ordens e intensidades, que afetam suas vidas no contexto das prisões. A fim de contribuir para esta discussão, o estudo buscou analisar a interseção das normas de gênero e das relações disciplinares identificadas na prisão, quando da experiência da maternidade, identificando controvérsias no plano dos valores e das relações de poder que as sustentam.

\section{Considerações metodológicas}

O sistema penitenciário no Brasil é composto dos sistemas penitenciários estaduais e do Sistema Penitenciário Federal. ${ }^{1}$ Levantamento realizado em maio de 2012, através de questionário enviado aos sistemas penitenciários dos 27 estados brasileiros e do Distrito Federal, sobre o número, a localização e o tipo de alojamento oferecido às gestantes, mães e seus filhos vivendo intramuros, registrou 
a existência de 419 mulheres convivendo com seus filhos na prisão. Para este estudo, foram escolhidas cinco unidades penitenciárias, de quatro estados, tendo por base o número de mulheres vivendo com seus filhos intramuros, bem como a diversidade de situações relacionadas a condições de alojamento e tempo permitido para permanência das crianças junto às mães. ${ }^{2}$ Foram entrevistadas 22 mulheres, gestantes e mães com filhos na prisão, e 19 profissionais que atuam no contexto da execução penal cujas práticas interferem na experiência da gestação e no exercício da maternidade nesse ambiente: gestores das unidades prisionais selecionadas para o estudo, pessoal da segurança, profissionais de saúde responsáveis pela assistência a mães e seus filhos na prisão, além de assistentes sociais e psicólogos.

Foram considerados critérios para inclusão no universo de mulheres participantes: diversidade de situações envolvendo o encaminhamento dos filhos, situações de risco na gravidez e problemas na saúde do bebê. $\mathrm{O}$ número de mães entrevistadas foi definido como o suficiente para que fossem abarcados os critérios expostos, que podiam se sobrepor.

Além das entrevistas individuais, foram realizados cinco grupos com as mulheres gestantes e com filhos na prisão e três com profissionais de saúde responsáveis pela assistência, utilizando-se a técnica de grupo focal (BARBOUR, 2009), escolhida por apresentar a vantagem de liberar a palavra, criando condições para que os sujeitos possam falar por si mesmos, expressando seus diferentes pontos de vista.

Os roteiros das entrevistas e grupos com as mães, gestantes e com os profissionais foram desenvolvidos a partir da revisão da legislação vigente, em especial a Lei de Execução Penal e a Resolução do CNPCP, que disciplina a permanência dos filhos das presas em ambientes prisionais; do material obtido a partir da leitura e revisão bibliográfica e da experiência de uma das pesquisadoras como psicóloga em prisões. Estas referências indicavam as desigualdades de gênero e os modelos de família, maternidade e infância (SANTA RITA, 2006; CERNEKA, 2009; GOMES, UZIEL, LOMBA, 2010; FIGUEIREDO, 2010; SANTOS, 2011) como categorias centrais no debate sobre a maternidade na prisão, bem como a importância de um olhar para os cuidados que requerem a gestação, o parto, o puerpério nesse contexto em que disciplina e segurança são priorizadas.

Assim, foram definidos os seguintes eixos temáticos: 1) percepções da maternidade na prisão e o papel do pai e da família; 2) percepção e cuidados na gravidez e no parto; 3) os cuidados e a assistência à saúde da criança; 4) a percepção 
do ambiente, das normas, as interações sociais; 5) a vivência da separação e encaminhamento dos filhos às famílias e/ou instituições. A partir destes cinco eixos de problematização, foi feita a análise do material coletado, cotejando-o com a literatura, visando à identificação de categorias que expressavam adensamentos de sentidos e possibilitavam a interpretação do material.

Para este artigo, em particular, focaram-se os aspectos que envolvem: i) percepçōes da maternidade na prisão; e ii) o papel do pai na percepção das mulheres mães.

\section{Aspectos éticos}

As entrevistas individuais e os grupos focais foram realizados nas unidades prisionais, em condições de privacidade e sem a presença de funcionários. Foram preservados o anonimato e a confidencialidade das informaçôes, especialmente perante a administração penitenciária. O Termo de Consentimento Livre e Esclarecido foi explicado e lido pela pesquisadora. A fim de evitar a identificação dos entrevistados, as entrevistas foram codificadas e os estados da federação selecionados não foram identificados.

Cabe informar, finalmente, que este artigo se origina dos resultados de estudo de abordagem psicossocial (DIUANA, 2014) que integra o projeto "Saúde Materno Infantil nas Prisões” (LEAL, 2016). Este projeto, que incluiu quatro estudos: saúde, psicossocial, jurídico e arquitetural, foi financiado pelo Ministério da Saúde e aprovado pelo Comitê de Ética em Pesquisa ENSP/FIOCRUZ. Prevêse a utilização para fins acadêmicos do material obtido.

\section{Resultados e Discussão}

Em nossas entrevistas com as mães emergiram de suas falas algumas categorias que expressavam modos de pensar e qualificar o exercício da maternidade que se estendiam e deslizavam sem muita diferenciação entre o "ser mãe" "na prisão" $e$ "fora dela", evidenciando sentidos que não se configuravam como específicos da prisão, embora adquirissem contornos próprios na situação de privação de liberdade. Em seu ponto de vista, "mães sempre se preocupam com os filhos" e "mães sofrem pela distância dos filhos". Estas falas sustentam qualidades maternas valorizadas. Preocupar-se com os filhos, cuidar deles e sofrer por eles são percebidas como realidades que sustentam o imaginário social acerca das qualidades morais de uma boa mãe. 
Muitas mulheres, antes de serem presas, eram responsáveis pela família, pela criação dos filhos e a manutenção da casa, e seu encarceramento piora a situação financeira da família, fragiliza os vínculos e força a reorganização familiar. Muitas dessas mulheres encontram dificuldades para referenciar os filhos no momento da prisão e a falta de açooes ou políticas públicas que deem suporte a essas crianças que deixam de contar com os cuidados e a proteção materna faz com que, muitas vezes, elas sejam entregues para outras famílias sem qualquer acompanhamento ou proteção. Após a prisão, as gestantes e mulheres com filhos são, em geral, transferidas das unidades prisionais onde estavam presas, localizadas, quase sempre, na proximidade de suas residências e de suas famílias, para a capital, o que aumenta os gastos e o desgaste da família para visitá-las, dificultando as trocas e interaçóes com suas redes de sociabilidade e o acesso a recursos sociais de apoio e proteção. Tudo isto restringe sua capacidade de ação e as coloca em situação de dependência perante a administração penitenciária tanto para cuidar dos filhos que estão longe, como daqueles que estão com elas.

$\mathrm{Na}$ prisão, o fechamento institucional e as regulamentações penais, a vigilância constante, a restrição do poder decisório das mães e a separação compulsória dos filhos promovem formas de viver a maternidade que se distinguem e ressignificam a relação com os filhos. Relações de poder, discursos e práticas nesse contexto geram tensionamentos e promovem formas peculiares de viver a maternidade. Neste estudo, para ressaltá-las, produziu-se três categorias analíticas distintas: a maternidade interrompida, a maternidade desautorizada e a maternidade exclusiva.

\section{Maternidade interrompida}

O vínculo com o filho nascido durante o encarceramento se constrói em conexão com a vivência simultânea da separação. Tanto pela expectativa da separação obrigatória findo o tempo permitido para a permanencia da criança, quanto pela vivência de ameaça de separação a qualquer momento em razão de problemas disciplinares. Todas estas incertezas presentes e futuras estão envoltas em normas e procedimentos pouco claros, céleres e com grande margem de discricionariedade da administração penitenciária (VENTURA; SIMAS; LAROUZÉ, 2015).

O dia a dia na prisão é regido por normas e regulamentos aos quais as mães devem se ajustar. Em casos de conflitos, delas entre si ou com a administração, a atribuição de castigos, que constitui a estratégia geral de ação adotada pelo sistema 
penitenciário, é aplicada. Nos casos considerados graves pela administração, a principal forma de punição consiste no encaminhamento da criança para aquele que será o responsável por sua guarda provisória e a transferência da mãe para a unidade de origem, promovendo a separação mãe-filho. Este risco de separação, onipresente nas falas das mães, constitui importante técnica modeladora dos comportamentos maternos na prisão. É por meio dela que a administração consegue exercer um controle ainda mais forte sobre as mulheres presas, e é o vínculo mãe-filho, incitado durante sua permanência junto à mãe, o principal suporte para isso. Como nos diz uma entrevistada:

Eu guardo a raiva dentro de mim pra não ter briga com ninguém. Eu fico tranquila, porque assim, eu penso no meu filho. Não quero que acontece nada de mal pra mim, porque eu tenho que ficar bem pra cuidar dele (MF).

Cuidar de si é cuidar do filho. Desse modo, controlar-se, "guardar a raiva”, são práticas que exercem sobre si mesmas para afirmarem-se como mães. Esta dinâmica, promovida pelo fortalecimento do vínculo mãe-filho e pelo risco constante de separação, também está presente nas decisões que envolvem a amamentação e o desmame.

Ainda que a amamentação seja sentida como importante momento de troca de afeto entre elas e seus filhos, como "coisa que aumenta a imunidade", "fortalece" e favorece a saúde e o desenvolvimento deles, sua continuidade ou interrupção também está marcada por este tensionamento. Entre algumas mulheres entrevistadas, havia a crença de que se os filhos estivessem sendo amamentados ao seio, elas poderiam ficar mais seguras de que eles permaneceriam com elas até o tempo limite. Esta crença sustenta-se na clara percepção de que sua importância para o filho é reconhecida pela administração principalmente por sua condição de nutriz.

Eu também não dou muita coisa pra ele acostumar com comida, por causa disso... eles vão ver que num tá mamando, então vão achar que tá mais fácil dele ficar na rua, né? Isso que eu não... nem insisto assim, muito. Quando eu dou alguma coisa pra ele comer e ele vira o rosto, eu nem dou mais (MF).

Já outras mulheres, desconfiadas do sucesso desta estratégia, preocupavam-se em desmamá-los, pois sabiam que havia um tempo limite para que seus filhos permanecessem junto a elas e acreditavam que, se eles já estivessem desmamados, sofreriam menos com a separação. O desmame precoce é, assim, em muitos casos, adotado como estratégia para facilitar a adaptação do filho à nova situação. 
Eu gosto de amamentar meus filhos, aqui eu vou ter que desmamar. Os outros [filhos], você não percebe, vai introduzindo outros alimentos... Como na rua a gente trabalha, a criança fica na creche, só mama à noite, é automático. Aqui não, a gente tem que ter o cuidado de tirar o peito (MF).

Desmamar o filho na situação de prisão não é fácil, nem para a mãe nem para o bebê, pois a vinculação intensa e quase exclusiva entre mãe e filho gera um apego entre eles que dificulta o desmame. Esta decisão, que implica uma renúncia materna, é, entretanto, compensada por possibilitar que reconheçam em si mesmas qualidades que se espera de uma mãe, altruísmo e abnegação em favor do filho. Qualidades que se encaixam nas normas de gênero e na produção de subjetividades dóceis que Foucault (2000) já apontou como sendo o resultado esperado da aplicação dos procedimentos disciplinares nas prisóes.

O que atrapalha [o desmame] é que a criança cria um vínculo com a mãe maior. Porque aqui ele fica comigo o dia inteiro. Eu não deixo ninguém pegar do meu colo. Ele fica muito comigo. Eu acho que é prejudicial para ele, porque eles ficam muito apegados e quando eles forem embora eles vão sofrer. Nós [as mães] também, mas a gente tem um controle e eles não (MF).

Esta percepção de que a convivência prolongada pode criar um apego entre elas e seus filhos, intensificando o sofrimento da separação, pode precipitar a decisão de encaminhar o filho para a família, ainda antes de atingido o tempo limite permitido para permanência. Para isto, também contribui a avaliação que fazem de que a "prisão não é lugar para criança”. Para elas, ao permanecerem na prisão, seus filhos estão, como elas, privados da liberdade. Têm clareza da privação de experiências que a permanência na prisão ocasiona a eles. Privação que envolve conhecer diferentes sabores, pois na rua "podem comer tudo que é bom”, diferentes espaços, ("podem ir à pracinha”), diferentes possibilidades de brincar, de se expandir em lugares abertos. Privação de vivências e de interações com outras pessoas, inclusive com irmãos e parentes que deveriam ser familiares e que, por causa da prisão, se tornam desconhecidos. Nesse sentido, procuram estabelecer critérios que lhes permitam decidir o que é melhor para eles, ainda que isto signifique sofrimento para elas.

Toda a violência da separação forçada e da adaptação obrigatória expressa na fala das mães é vivida de maneira menos conflituosa se o acolhimento pela família permite expectativas da manutenção do vínculo ou até mesmo o restabelecimento de vínculos partidos, mas se torna uma fonte de dilemas 
quando, ao contrário, esta ligação é difícil ou não é mais possível e o limite temporal impõe o encaminhamento do filho para a guarda de outro.

Nesses casos - de impossibilidade de permanecer com seu filho ou de sair em liberdade junto com ele - impõe-se o encaminhamento do filho para um abrigo, o que não é bem aceito pelas mães. Elas são suas mães, estão cuidando deles, e, apesar disso, os filhos serão separados delas para serem entregues a uma instituição que as mães não reconhecem e não confiam. Temem que sejam maltratados, que elas não consigam mais vê-los e que não possam recuperar sua guarda quando saírem da prisão. Assim sendo, procuram retardar ao máximo o momento da separação, que se converte em situação de grande angústia e remordimentos.

Ai! Deus me livre! Não tenho ninguém pra deixar o meu filho. Daí eu não sei o que seria de mim. Se eu não conseguir sair com ele, eu não sei... Eu vou me desaminar. Vai que eu já estou no fim [da pena] e não sei e daí saber que o meu filho vai pra um abrigo... (MF).

Nesse sentido, a demora na definição da situação jurídica, que torna mais difícil a decisão materna de encaminhar o filho ou aguardar para que possam sair juntos, constitui outro aspecto torturante para estas mulheres. Muitas, cerca de $90 \%$, segundo Leal (2016), foram presas quando estavam grávidas, a maioria delas antes mesmo de serem julgadas, e não sabem sequer se serão absolvidas ou condenadas ou de quanto tempo será suas penas. Não sabem, portanto, se e por quanto tempo poderão ficar com seus filhos junto a elas, mas acreditam que, se forem boas mães, cuidadosas, e não "arranjarem problemas" o "Juiz não vai levar ele embora". A demora no julgamento se constitui então, em outra forma de modelagem do comportamento destas mulheres, que se veem submetidas a padrôes imaginários de boa maternidade como tentativa de controlar uma situação sobre a qual não têm nenhuma interferência e diante da qual são completamente vulneráveis.

\section{Maternidade desautorizada}

Além desta vulnerabilidade na construção do vínculo mãe-filho, em conexão com a expectativa de separação imposta pela situação de encarceramento, outro aspecto conflitual também é acionado: o poder e dever de cuidar do filho e de integrá-lo em seu ambiente familiar e sociocultural é permanentemente confrontado com as restrições impostas a seu poder decisório e sua autoridade sobre os filhos. Os cuidados maternos na prisão estão configurados pelas 
condições espaciais, pelos recursos disponíveis, pelas normas de funcionamento e pelos conflitos decorrentes de situações que muitas vezes se chocam com as práticas e valores socioculturais e familiares associados à criação das crianças.

De modo geral, não há local próprio nem permissão para que as mães cozinhem nem que as famílias forneçam alimentação para as crianças, a não ser alguns complementos alimentares. A alimentação "de panela” fornecida para elas, feita no refeitório da unidade, é vista como inadequada ("tem até pimentão"), contaminada ("na comida do meu guri já veio cabelo"), preparada sem a devida higiene ("elas não usam luva nem touca") e causa de doenças ("por causa do alimento mal cozido").

A imposição de certo tipo de alimentação às crianças adquire para estas mulheres o sentido de desvalorização de sua condição materna e de seu deverpoder de decidir o que é melhor para o filho ("Aqui a gente é mãe, mas elas querem mandar no jeito da gente criar nossos filhos"). Também as rotinas e horários constituem constrangimentos à liberdade das crianças e à autonomia das mães, já que as crianças e as mães precisam se ajustar a estes horários, que não contemplam diferenças de idade das crianças e de suas necessidades.

Aqui as crianças não podem dormir na hora que quer, tem que ser na hora que as guardas quer. Não podem comer na hora que quer, se não comer não pode guardar a comida pra ele, se não comer naquela hora não pode comer depois" (MF).

O modo como as mães cuidam das crianças é supervisionado pelas funcionárias, que nem sempre concordam com a maneira como elas cuidam dos filhos, interpretando como falta de zelo e de educação, falta de estrutura familiar e de vínculo afetivo com a família, ou mesmo como falta de amor pela criança comportamentos que as mães qualificam como "deixar ela aprender a se virar" ou "deixá-las se resolverem entre si". Este controle e avaliação se expressa na fala de uma agente penitenciária entrevistada:

Aqui a maioria se dedica e cuida bem do filho, mais como todo lugar tem uma minoria aí que a gente percebe que não tem amor nenhum pela criança, sabe? As crianças estão caindo, elas estão sentadas, a criança bem pequenininha caindo ela não tem coragem de levantar e atender para a criança não se machucar. Às vezes a gente fala: 'aí, você, não viu a criança caindo?' [elas respondem] 'Não. Ela tem que aprender'. Então você vê que não têm o comprometimento e o amor de mãe, não têm. Elas usam o filho pra obter benefícios pra elas (...) E a influência da mãe com a criança, a gente é que tem que avaliar. Porque eu não concordo, tem mãe que não deveria ter jamais contato com filho porque ela só passa coisa ruim pro filho, ensina só o que não presta (AP). 
Entre a demanda dirigida às mulheres para que se responsabilizem por seus filhos e a condição de privação de liberdade, na qual têm sua capacidade de agir e decidir constrangidas pela vigilância e pelo controle disciplinar, a atenção à saúde das crianças constitui uma das maiores fontes de tensão e insatisfação das mães e de conflitos com a administração penitenciária. Nesses casos, as mulheres presas sentem-se pressionadas entre ameaças veladas ou claras de serem punidas ou de verem os problemas de saúde dos filhos se agravarem por demora ou desassistência à saúde. Como não há assistência pediátrica intramuros, em uma base cotidiana, nem tampouco durante a noite ou nos finais de semana, o tratamento das crianças encarceradas com suas mães coloca a demanda pela saída da unidade. A avaliação da "necessidade" desta assistência, feita informalmente tanto pelo pessoal da segurança, como por pessoal da enfermagem da unidade prisional, não é reconhecida pelas mães como uma avaliação qualificada nem isenta, o que gera muita tensão nesses momentos, pois, ao provocar demora no atendimento de saúde das crianças, podem aumentar as chances de agravamento de seu estado de saúde.

Esta "triagem" pelo pessoal da segurança se sustenta no discurso de que as mães usam as crianças para "passear", desqualificando a preocupação e o saber maternos acerca da saúde de seu filho, retirando o poder decisório que decorre de sua responsabilidade com a proteção e o cuidado dos filhos e impondo às mulheres presas uma necessidade de luta para afirmação e reconhecimento de seu lugar de mãe. Quando consegue fazer valer sua demanda de levar seu filho à assistência de saúde extramuros, ou a mulher acompanha o filho, escoltada e algemada, ou ela o entrega para que seja levado ao serviço de saúde, conduzido por um profissional de saúde ou por um agente penitenciário, conforme o funcionamento previsto por cada estado da federação.

...essa semana fui no posto e até a mulher ficou com medo de mim. Sendo que eu estava de algema, estava com o guri no colo e a mulher falou... a mulher que faz vacina nele... ela falou: 'Ah! Não! Dá pra abrir a porta? Eu vou ficar do lado de fora, porque eu tenho medo.' Falou assim, sabe? E tremeu e não conseguia nem escrever direito... (MF).

Tem uns guardas que levam ao médico, tem outros que não. Só se a criança tiver febre. A gente não vai. A gente fica por fora. A gente não tá ali pra ouvir o que o médico fala. A gente ouve da boca da guarda. Eu acho que a mãe devia ir também pra o médico dar a instrução pra gente, não pra outra pessoa (MF). 
Nesse contexto, seu poder-dever de cuidar do filho e de protegê-lo requer luta e impõe muitas humilhações, e ainda que elas evoquem os direitos de seus filhos e suas obrigações maternas para lutar por eles, sabem que nem sempre serão ouvidas.

As crianças não estão presas! É um direito! Eles [os responsáveis pela escolta] têm que zelar pela saúde deles [dos filhos]! Pela vida deles também! (MF).

Se brigar, vão te mandar para fora da cadeia, vão te dar bonde. Eles falam que a culpa toda é nossa, mas ninguém se coloca no lugar, a gente está presa com filho, a gente quer levar para atendimento, começa a demorar. Se a gente não insistir o que pode acontecer? (MF - Grupo focal).

\section{A maternidade exclusiva}

Diante de um estado de restrição total de sua autonomia, das parcerias e apoios socioafetivos e institucionais usualmente encontrados extramuros, as mulheres presas com seus filhos acabam tendo que responder sozinhas pela segurança, pela saúde e pela vida do filho com ela encarcerado. Este status quo instala as mulheres num lugar de intensa ansiedade, e de culpabilidade, por não conseguirem manter seu compromisso de cuidar e proteger seu filho, acabando por intensificar ainda mais o sentimento de vínculo da mulher com seu filho, fazendo com que vivam esta relação de modo diferente das anteriores. "Foi como se fosse meu primeiro filho porque eu to me envolvendo muito com ele porque eu cuido dele vinte e quatro horas" (MF).

Este filho que está junto com ela, que sofre como ela, adquire um significado especial, diferente dos outros filhos.

Meus outros filhos, eles têm a minha família, têm a família do pai deles. Este filho só tem a mim. Então eu me sinto tão responsável por ele, pelo futuro dele, que mudou a minha vida. Pelo fato dele ter nascido aqui e não ter o mesmo privilégio que os outros (MF).

Por outro lado, a vida com o filho na prisão torna mais suportável o sofrimento e as protege da vivência da solidão. "Me sinto abandonada. Toda vez eu agradeço a Deus pelo meu filho estar aqui, entendeu? Eu não ia aguentar, ficar sem ele, porque é a primeira vez que to presa" (MF).

Sem diversificação de vínculos (Leal verificou que 39,4\% das entrevistadas não receberam nenhuma visita nem durante a gestação nem depois do nascimento do filho), em um ambiente hostil, a presença física se torna fundamental para eles e a separação ocasiona insegurança e medo. Mesmo reconhecendo que ali 
não é um bom lugar para a permanência dos filhos, acreditam que, com elas, eles estarão protegidos. Uma cena retratada por profissionais de saúde entrevistados revela, igualmente, a intensidade deste vínculo:

[...] ele foi chorando. Aí o rapaz da ambulância deu pra ele um chocolate, o chocolate não fez efeito nenhum, ele foi chorando e voltou chorando. A hora que ele chegou, a mãe estava agachada na grade. Ele foi correndo tanto pra encontrar com a mãe que ele bateu a testa na grade, mais isso não fez diferença, ele abraçou o pescoço da mãe por entre a grade, ficou tão agarrado que não queria nem que abrisse a grade pra entrar. Então, é aquele medo, porque ele só conhece essa pessoa (PS).

As mães, por sua vez, só se sentem seguras se tiverem seus filhos sob seus olhos, não confiando em ninguém para cuidar deles. No entanto, cuidar dos filhos em tempo integral (" 24 por 48 ”, como elas dizem), sem ninguém com quem dividir as tarefas cotidianas, dia após dia, em um ambiente hostil e inseguro, é algo muito estressante. Como se expressa nas falas de mães entrevistadas,

As mães não aguentam ficar o dia todo na creche porque estressa muito, muitas crianças, cuida de um, cuida de outro, um faz cocô o outro faz xixi (MF).

Às vezes ele fala: mãe, mãe. Ele mostra, parece que ele quer que eu de atenção pra ele. $\mathrm{E}$ as vezes eu não tenho paciência, pelo lugar, entendeu? As vezes o tempo que eu to aqui me estressa, entendeu. Uma que chegou lá já quer falar mais alto... tem pessoas que são ignorantes... (MF).

Isto faz com que desenvolvam algumas estratégias para “descansar” um pouco desta maternidade total, em tempo integral; comportamento que, como relatado por uma enfermeira entrevistada, é malvisto:

Outra cultura, outra criação. Pra mim foi um choque, ver que elas simulavam uma queda do bebe, para dispensar os cuidados do bebe para a enfermagem e poder ter um tempo para ela ficar sozinha. Diziam que tinham caído, mas não tinham marcas (PS - grupo focal).

Assim, nesse contexto, cuidar exclusivamente dos filhos envolve muitas tensões, muitos confrontos e também muitos sacrifícios. De modo geral, as mulheres que estão com seus filhos junto a elas não exercem atividades laborativas nem tampouco têm qualquer atividade educacional ou cultural que seja remunerada ou classificada para remição de pena (cada três dias de trabalho reduz um dia de pena). Esta restrição imposta pela maternidade exclusiva, que dificulta o acesso a direitos, agrava também a situação de dependência econômica da família, da administração penitenciária, de instituições que prestam assistência religiosa nos presídios ou de outras presas, sendo um dos fatores que contribuem decisivamente 
para que algumas mães decidam encaminhar seus filhos para a família assim que possível, para poderem voltar à unidade prisional, trabalhar e buscar uma remuneração e a redução da pena.

$\mathrm{Na}$ fala da administração penitenciária, o exercício exclusivo da maternidade durante o encarceramento se deve a um entendimento de que a criança está na unidade prisional em razão da amamentação e da importância da convivência mãefilho, que, por isto, deve se dedicar integralmente a seus cuidados. Esta leitura, que reproduz a divisão sexual do trabalho, que atribui à mulher o cuidado e a criação dos filhos e, simultaneamente, desvaloriza sua importância social, esconde também a falta de alternativas/apoios institucionais para os cuidados maternos.

Quando as mães avaliam a intensificação do vínculo mãe-filho em decorrência do exercício exclusivo da maternidade, há diferenças entre elas. Algumas consideram que não ter outra atividade a não ser cuidar do filho é bom, já que assim se sentem mais envolvidas com eles, o que não estaria acontecendo se estivessem na rua, porque estariam trabalhando e teriam que deixar seus filhos com as mães, ou com outra pessoa. Outras consideram que com este filho puderam ter um laço que não tiveram com os anteriores, "por causa da droga que deixa a gente seca”. No entanto, ressaltam que isto não significa que seja bom estar presa com o filho, mas que gostariam de poder ter esta condição em liberdade. Outras dizem que em liberdade também davam atenção aos filhos e tinham por eles o mesmo afeto, sem que fosse preciso dedicar-se exclusivamente a eles e que gostariam de poder ter outra atividade, pois assim é "muita prisão".

Mas havia também aquelas cujos filhos nascidos durante o encarceramento precisavam de cuidados especiais, como nos casos de bebês soropositivos, com sífilis ou com Síndrome de Down, que não apenas desejavam, mas sabiam que cuidados intensivos eram necessários para seus bebês. Cuidados não apenas delas, mas de seus familiares e, sobretudo, de profissionais especializados a quem pudessem ter acesso ao direito à saúde. Para elas, era clara a violação dos direitos de seus filhos aos cuidados e à proteção familiar, pois nem elas nem suas famílias poderiam suprir, separadamente, as demandas colocadas pelos problemas de saúde de seus bebês. A privação da liberdade representava uma violência que se exercia sobre elas e seus filhos, gerando angústia, ansiedade, depressão e revolta, o que também foi observado por Catito (2014). Sentiam que sua pena estendia-se a seus filhos, que "não merecem isso". 
Nesse contexto, o debate em torno da dedicação integral à maternidade não pode ser separado das restrições impostas à autonomia da mãe para decidir sobre os cuidados e educação dos filhos; do cerceamento à busca da atenção profissional que ela julga necessária ao bem-estar, à vida e à saúde deles; nem tampouco da forma coercitiva e generalizada pela qual esta dedicação é imposta. Precisa ainda considerar a imposição de desligamento da convivência mãe-bebê após este intenso período de convivência e a simultânea supressão de outras pessoas, familiares, amigos, vizinhos e instituiçóes sociais, de saúde e educacionais, que na vida cotidiana apoiam, participam e interagem na relação mãe-bebê. Finalmente, cabe ainda considerar a invisibilidade em que é deixado o pai nas análises e nas práticas que envolvem a maternidade nesse cenário.

A discussão da paternidade na prisão não foi o propósito deste estudo. A importância de discutir este tema apareceu no decurso do próprio processo de pesquisa, evidenciada pela expressiva ausência do pai, tanto no cotidiano, como nas falas dos entrevistados. O aprofundamento deste tópico requer um estudo específico, em que os pais sejam ouvidos. Neste artigo, discutiremos apenas a percepção da paternidade na fala das mães. Assim, só indiretamente pode ser feito este debate.

Nas unidades prisionais estudadas, é voz corrente entre agentes penitenciários, técnicos e gestores que os pais abandonam os filhos e suas companheiras presas. Este discurso reforça uma leitura em que as mulheres são vistas como vitimas de homens que não assumem suas responsabilidades. Embora esta fala também apareça nos discursos das mulheres, observou-se que outros sentidos são dados por elas à presença ou ausência do pai, e que o desejo da presença e o reconhecimento da paternidade, para além da condição de o pai estar preso ou não, de visitála ou não, de ter ou não envolvimento com práticas ilícitas, envolvem seu relacionamento com ela e com os filhos. Havia casos em que a presença dos pais era desejada e eles eram presentes, visitando e respondendo pela assistência material do filho. Em outros, os pais, em liberdade, cuidavam dos filhos que ficaram com eles e isto os dispensava de visitar a mulher. Havia ainda os que estavam presos e que acompanhavam a vida e o crescimento do filho por meio de correspondência, participando, inclusive, das decisões sobre ele. Mas também havia casos em que o filho era "fruto de uma aventura", sem que o pai sequer soubesse do nascimento, e outros em que os pais eram vistos como irresponsáveis, 
não sendo um "bom exemplo" para o filho, o que fazia com que as mulheres não desejassem, inclusive, que ele soubesse ou reconhecesse sua paternidade. Outro aspecto importante para as mulheres consiste no reconhecimento pelos pais dos seus direitos maternos. Quando sentem que o pai ou sua família podem tentar lhes "tirar o filho", elas não aceitam sua presença nem reconhecem sua paternidade. Assim, a participação pode ser percebida como desejável se representa apoio nas decisões e na proteção dos filhos, ou, o contrário, caso seja vista como um risco para a formação e a vida dos filhos e para o reconhecimento de sua maternidade. Esta confiança ou este receio se expressam também na aceitação ou recusa da assistência e apoio da família paterna.

No entanto, para além da relação que possa haver entre eles, a ação do sistema penal aparece como decisiva na presença/ausência do homem/pai junto à mulher e ao filho. Nos estados pesquisados, o pai preso ébuscado apenas para o cumprimento da obrigação de registro das crianças. As administrações penitenciárias não proporcionam ao pai que está preso nem mesmo uma oportunidade para que possa conhecer o filho recém-nascido, menos ainda para o convívio entre eles por meio de visitas sistemáticas. Quanto aos pais que se encontram em liberdade, mesmo quando mantêm vínculo com a companheira presa e registraram os filhos, e ainda que sobre eles não recaia o descrédito pelo envolvimento com o crime, sua participação no cuidado do filho também é cerceada. Não podem levá-los para uma visita a casa, à família e aos irmãos ou mesmo para passear. Isto só é permitido mediante autorização judicial. A participação do pai restringe-se à vista semanal e ao fornecimento de suprimentos para o bebê. Em um dos estados pesquisados, inclusive no momento de encaminhamento da criança para casa, para que ele possa levar o filho é preciso autorização judicial. Como expressou uma assistente social entrevistada: "querendo ou não, a gente entra naquela cultura, que se não tiver a presença de uma mulher a gente não sabe como está essa criança. " É com base nesta naturalização do cuidado com os filhos como uma prática essencialmente feminina, que o pai é colocado na sombra e afastado da cena, obscurecendo o agenciamento operado entre as práticas penais e normas de gênero na produção desta ausência. Assim, é possível pensar que, se as desigualdades de gênero produzem efeitos sobre o exercício da paternidade na prisão, elas são (re) produzidas pela ação institucional que as reforça e se apoia nelas para manter afastados os pais. 


\section{Considerações finais}

Como se viu neste estudo, a maternidade durante o encarceramento está longe de poder ser adjetivada como "voluntária, prazerosa e socialmente amparada" (DINIZ, 2004), como hoje reivindicam os movimentos sociais de mulheres. Ao contrário, nesse contexto, as mulheres estão expostas a muitas violências decorrentes de seu encarceramento, que fazem com que o sofrimento e o sacrifício pelo "bem dos filhos" sejam aceitos como parte integrante do exercício da maternidade, em especial pelas mulheres que desejam permanecer com seus filhos junto a elas na prisão ou que encontram dificuldades para encaminhá-los a pessoa de sua confiança.

Para elas, preocupar-se com os filhos, cuidar e se responsabilizar por eles são práticas que sustentam as qualidades morais de uma boa mãe, e na prisão, o tensionamento entre este modo de pensar e qualificar a maternidade e as possibilidades de sua realização engendra práticas e opera distinções entre "boas mães” e outras, que não conseguem suportar ou recusam as exigências impostas pela maternidade durante o encarceramento.

Alguns mecanismos institucionais, em especial, atuam neste processo: a ameaça de separação do filho; as restrições impostas ao poder decisório da mãe; a limitação de parcerias e apoios socioafetivos e institucionais e a incerteza quanto a sua situação jurídica. É sua interação com a maternidade normativa, que incita as mulheres a tomarem para si o poder e a responsabilidade pela vida e o cuidado de seus filhos, que, nesse contexto, vai promover uma intensificação dos vínculos mãe-filho; a impotência e a ansiedade diante do dever de protegê-lo; a insegurança que a responsabilidade quase exclusiva por eles produz, bem como a angústia decorrente da separação compulsória, que constituem modos de viver a maternidade próprios ao contexto da prisão.

Trata-se, portanto, de um exercício da maternidade tensionado ao extremo por uma dupla ordem disciplinar: por um lado, uma ordem penal que reduz a mulher à condição de infratora que deve ser controlada e docilizada em nome da segurança social; e por outro, normas de gênero que têm na maternidade um dispositivo de distribuição de poderes e de controle dos corpos, da sexualidade e da vida das mulheres. Os mecanismos de punição, de recompensa e a manipulação de privilégios, característicos do penitenciário, ao se integrar a outras práticas de controle que as mulheres-mães realizam sobre si em função do cuidado e proteção 
dos filhos, aumentam o controle que a administração penal exerce sobre elas, intensificam assimetrias e vulnerabilizam concretamente estas mulheres, violam seus direitos reprodutivos, expondo-as e a seus filhos a sofrimentos psíquicos e morais perante os quais têm limitados recursos para se defender.

Nesse cenário de desigualdade de gênero e de violências institucionais, impõe-se à reflexão a necessidade de ações normativas estatais que limitem o extraordinário poder que a administração penitenciária tem sobre a vida destas mulheres e seus filhos, bem como a urgência de efetiva implantação de leis e políticas públicas que possam ampliar os recursos para atenção à maternidade e à infância na prisão. Para além disto, no entanto, verifica-se que é a própria prisão que precisa ser afastada a fim de que as mulheres possam viver suas maternidades em um contexto de menos opressão. Intervenções judiciais se apresentam como importantes instrumentos para alteração deste quadro. As Audiências de Custódia, por exemplo, se atentarem para a condição de gravidez da mulher, podem influenciar significativamente esta situação, visto que $90 \%$ das gestantes e mães que convivem com seus filhos nascidos durante o encarceramento já estavam grávidas no momento da prisão e que, nesses casos, a adoção de intervençōes penais alternativas à prisão está prevista na legislação brasileira e encontra-se destacada entre as boas práticas recomendadas pela ONU (2010).

No entanto, para que não se advogue apenas pela transferência da prisão para o domicílio, é preciso questionar a lógica das políticas públicas, que, pautadas num projeto de Estado, de inspiração neoliberal, vêm reduzindo seu compromisso com a garantia dos direitos sociais da população ao mesmo tempo que amplia a intervenção penal como estratégia de controle da pobreza (WACQUANT, 2008) e de outras formas de vida contestadas. ${ }^{3}$

\section{Agradecimentos}

Às mulheres presas que nos confiaram suas reflexões. A Maria do Carmo Leal e Alexandra Sanchez, pela parceria produtiva e, especialmente, a Bernard Larouzé, por suas preciosas sugestôes ao longo do trabalho. Ao Departamento Penitenciário Nacional (DEPEN), pelo apoio à pesquisa; e à Secretaria de Atenção à Saúde do Ministério da Saúde, pelo financiamento. 


\section{Referências}

ARÁN, M.; PEIXOTO JR., C.A. Vulnerabilidade e vida nua: bioética e biopolítica na atualidade. Rev. Saúde Pública, v. 41, n. 5, p. 849-57, 2007.

BARBOUR, R. Grupos focais. Porto Alegre : Artemed, 2009. 216p.

BRASIL. Ministério da Justiça. Departamento Penitenciário Nacional. Sistema Integrado de Informaçôes Penitenciárias - InfoPen. Referência: 06/2014. Disponível em: <http://www. justica.gov.br/seus-direitos/politica-penal/transparencia-institucional/estatisticas-prisional/ relatorios-estatisticos-analiticos-do-sistema-prisional>. Acesso em: maio 2016.

. Presidência da República. Secretaria Especial de Políticas para as Mulheres. Grupo de Trabalho Interministerial. Reorganização e Reformulação do Sistema Prisional Feminino - 2008. Brasília: Presidência da República. Secretaria Especial de Políticas para as Mulheres, 2008. 196p. CATITO, F.G.L. Depressão e sofrimento emocional durante a gravidez e separação dos filhos em mulheres encarceradas no Estabelecimento Prisional Feminino de Viana em Luanda, Angola. 2014. 146f. Dissertação (Mestrado) - PUC-SP, São Paulo, 2014.

CERNEKA, H.A. Homens que menstruam: considerações acerca do sistema prisional às especificidades da mulher. Veredas do Direito. Belo Horizonte, v. 6, n. 11, p. 61-78, jan./ jun. 2009.

CORRÊA, M.C.D.V.; ARÁN, M. Tecnologia e normas de gênero: contribuições para o debate da bioética feminista. Revista Bioética, v. 16, n. 2, p. 191-206, 2008.

DINIZ, S. Maternidade voluntária, prazerosa e socialmente amparada. Breve história de uma luta. São Paulo: Coletivo Feminista Sexualidade e Saúde, 2004.

DIUANA, V. Módulo Psicossocial. In: LEAL, M.C.; SANCHEZ, A. (Coords). Saúde materno-infantil nas prisôes. Rio de Janeiro: Escola Nacional de Saúde Pública - Fundação Oswaldo Cruz, 2014, p. 67-157. Relatório.

DIUANA, V. et al. Direitos reprodutivos das mulheres no sistema penitenciário: tensões e desafios na transformação da realidade. Ciência \& Saúde Coletiva. Rio de Janeiro, v. 21, n. 7, p. 2041-50, jun. 2016.

FIGUEIREDO, C.A.; SANTOS, M.B.S.; NASCIMENTO, O.T. Tempo de ser mãe reflexões sobre a experiência da maternidade no sistema prisional do Estado do Rio de Janeiro. In: SEMINÁRIO INTERNACIONAL FAZENDO GÊNERO 9- DIÁSPORAS, DIVERSIDADES, DESLOCAMENTOS. 23 a 26 de agosto de 2010.

FOUCAULT, M. Vigiar e Punir: o nascimento da prisão. Trad. Raquel Ramalhete. 22. ed. Petrópolis: Vozes, 2000. 288p.

GOMES, A.B.F.; UZIEL, A.P.; LOMBA, D.E.N. Singularidades da maternidade no sistema prisional. In: SEMINÁRIO INTERNACIONAL FAZENDO GÊNERO 9 DIÁSPORAS, DIVERSIDADES, DESLOCAMENTOS.23 a 26 de agosto de 2010. 
LEAL, MC et al. Nascer na prisão: gestação e parto atrás das grades no Brasil. Ciência \& Saúde Coletiva. Rio de Janeiro, v. 21, n. 7, p. 2061-69, jun. 2016.

Organização das Naçōes Unidas (ONU). Regras de Bangkok. 2010. Disponível em: <http:// carceraria.org.br/wp-content/uploads/2012/09/Tradu\%c3\%a7\%c3\%a3o-n\%c3\%a3ooficial-das-Regras-de-Bangkok-em-11-04-2012.pdf>. Acesso em: maio 2016.

SANTA RITA, R.P. Mães e crianças atrás das grades: em questão o princípio da dignidade humana. 2006. Dissertação (Mestrado) - Programa de Pós-Graduação em Política Social. Departamento de Serviço Social. Universidade de Brasília, Brasília, 2006.

SANTOS, R.C.S. Maternidade no cárcere: reflexões sobre o sistema penitenciário feminino. 2011. 121 f. Dissertação (Mestrado em Política Social) - Universidade Federal Fluminense, Escola de Serviço Social, Niterói, 2011.

VENTURA, M.; SIMAS, L.; LAROUZÉ, B. Maternidade atrás das grades: em busca da cidadania e da saúde. Um estudo sobre a legislação brasileira. Cad. Saúde Pública. Rio de Janeiro, v. 31, n. 3, p. 607-619, mar. 2015.

WACQUANT, L. As duas faces do gueto. São Paulo: Boitempo, 2008. 156p.

\section{Notas}

${ }^{1}$ Existem no Brasil quatro unidades de segurança máxima mantidas pelo Governo Federal: Campo Grande-MS, Catanduvas-PR, Mossoró-RN e Porto Velho-RO. No entanto, como não há gestantes nem crianças no sistema federal, elas não foram incluídas no estudo.

${ }^{2}$ No levantamento preliminar realizado em maio de 2012, verificou-se que havia um estado onde as crianças não podiam ficar com as mães, sendo encaminhadas para outro guardião logo após o nascimento (PA); outros em que elas podiam ficar até um ano (CE MG PE e RS) ou dois anos (PI); e um único caso onde elas podiam permanecer até seis anos (PR). Nos demais estados, as crianças permaneciam até os seis meses de idade. Vale ressaltar que este quadro se alterou desde então.

${ }^{3}$ A. Diuana realizou o trabalho de campo, análise do material, concepção e redação do artigo. M. Corrêa e M. Ventura contribuíram na concepção do artigo, discussão dos resultados e revisão do texto. 
Women in Brazilian prisons: tensions between punitive disciplinary order and maternity prescriptions

Aiming to contribute to the debate about maternity in prison, this study analyzed the intersections of gender norms and disciplinary relationships in this context, identifying controversies regarding the values and power relations that sustain them. To that end, she interviewed 22 women - pregnant women and mothers with children in prison - in four Brazilian states, and 19 professionals working in this environment, in addition to five groups with pregnant women and mothers and three with health professionals. It was observed that institutional closure, penal regulations, constant vigilance, restriction of mothers' decision-making power and compulsory separation of children generate tensions and promote peculiar forms of motherhood. Three different analytical categories were produced: interrupted maternity, unauthorized maternity and exclusive maternity. It was concluded that the disciplinary mechanisms characteristic of the penitentiary, by integrating themselves with the self-control practices that mothers perform in function of the care and protection of their children, concretely make these women vulnerable, exposing them and their children to psychic sufferings and moral. It is suggested the need for normative interventions and legal measures, as well as public policies that replace criminal intervention as a strategy to control poverty and other contested ways of life.

> Keywords: gender; women; motherhood; parenthood; prison; rights. 